\title{
Editorial
}

\section{Cooking as a healthy behaviour}

Nutrition policy makers often express concern about a loss of cooking skills in societies where more and more food is prepared and eaten away from home ${ }^{(1)}$. There are several reasons for this concern. They include the loss of basic domestic skills that give people control over individual and household food supply, a loss of knowledge of ingredients and their use, as well as an ignorance regarding cooking methods making healthy home cooking less likely. This leaves the field open for less healthy ready-to-eat alternatives. Policy makers are also aware of changes in the social role of food, which has its own health connotations ${ }^{(2)}$

It is problematic to try to reinstall the lost opportunities to cook and it may not even be possible. In the case of the aged, there may be less access to food to cook and to facilities for cooking, or a loss of the ability or inclination to cook. Loss of appetite is also of concern in older adults. For these reasons and combined with increasing frailty and loss of independence, Meals on Wheels and other home delivery services have become important nutritional support systems for this age group. There is certainly strong evidence to support the importance of nutritious food throughout the life cycle. There has been little evidence, however, about whether food preparation and cooking might affect health and even survival. This issue of Public Health Nutrition provides some of the evidence required $^{(3)}$

In a 10-year study, out of a representative sample of free-living elderly people aged $65+$ years in Taiwan, those who cooked most frequently ( $>5$ times/week, compared with never) had only $59 \%$ of the mortality risk ${ }^{(3)}$. They also walked and shopped more, ate less meat and more vegetables, but adjustment for these and other possible confounders did not alter the findings. Women benefited more than men from cooking. A 2-year delay in the survival analysis led to similar findings. The differences that were found could perhaps partly be explained by a 'healthy worker effect', whereby those who are healthy have the energy to cook and live longer, rather than the interpretation that the ones who cook become thereby the healthiest. The models studied, however, also took account of shopping, co-morbidities, physical function and chewing ability. Thus, cooking behaviour favourably predicted survivorship in the study.

Cooking is not a single activity. It involves a considerable physical and social skills set; it requires fine and gross motor skills, cognitive abilities, memory and - not least - a validation of life patterns. It is an 'active engagement'. One reason women why may benefit most from cooking later in life is that they are cooking for someone else, as they have probably always done: that is, they are cooking with greater purpose than simply preparing meals for themselves. Even single women benefited from frequent cooking - the effect of 'active engagement'. It may also be that preparing food stimulates the appetite, which often declines with age, a decline that brings its own nutritional challenges. Own cooking also means having possibilities for seasoning to accommodate own taste preferences, which may also be altered with age.

It appears that cooking is an important part of a healthy lifestyle. In Chen et al.'s study ${ }^{(3)}$, those who cooked frequently went shopping - often walking or cycling. They ate a more nutritious diet, as evidenced in their higher consumption of vegetables. They did not smoke or drink alcohol (it would be interesting to know if the protective effects of cooking overrode any negative effects of smoking and alcohol). Some cooking, particularly making noodles or pasta, can be physically demanding, providing additional strength training. Using fresh ingredients also means more frequent food shopping - which then stimulates physical activity and provides weight-bearing exercise and vitamin D from being outdoors. Frequent shopping, too, predicts longer lives ${ }^{(4)}$.

One of the striking things in Chen et al.'s study ${ }^{(3)}$ is that women with less education seemed to cook more and have higher survival. It might be asked whether we are looking at survival, or at healthy ageing? Is it because more highly educated women did less cooking at earlier stages of their lives? Are they less skilled as cooks? Or do they see cooking as an activity that is less valuable as part of their identified skills? Is that also the issue with men - is their identity connected with their work and do they regard domestic skills as second-rate?

It is encouraging to see the new wave of interest in cooking, in numerous television shows. There are also examples of an increased interest in cookery classes notably for men in the $\mathrm{UK}^{(5)}$, which may help develop skills for an improved social life as well as providing a practical repertoire of recipes. Well-thumbed iconic domestic recipe books remain food intake insurance policies! But with this new wave of interest in cooking, the crucial thing is to develop cooking as a practical and practicable interest, the by-products of which are likely to be good nutrition and sociability. Cooking as a competitive sport or gourmet 'Michelin guide' cooking 
(as in series such as MasterChef) has few lessons for everyday cooking. Introducing or preserving cooking in schools and encouraging children to cook at home with their parents and grandparents would be a valuable start for lifelong skills. Introducing cooking into after-school programmes could also be a valuable way to provide children with a lifelong knowledge in basic cooking and possibly also equip them with a more developed palate, able to sense the difference between a home-cooked meal and ultra-processed foods.

On a day-to-day basis, we need to ensure that people are able to maintain healthy life habits related to food purchasing, storing and preparation - and urban planning is crucial $^{(6)}$. (Are there green spaces? Are there shops to walk to? Is fresh produce readily available and affordable?) We might also look at kitchens and kitchen equipment in public housing. Just as we give picture books to newborn babies, perhaps we need to ensure there is a good cookery book, a stockpot and a wok in every house, not to mention a sanitary, easy-to-maintain kitchen and storage area.

Cooperation between the public health nutrition workforce, along with revitalised 'home economists' and good cooks who motivate their audiences about cooking and eating healthy foods, has arrived. But it is well overdue and still under-developed. Such collaboration can be further encouraged by the knowledge that frequent cooking might presage a longer life and possibly also a happier one.

Rita Erlich ritaerlich@gmail.com.au www.ritaerlich.com.au

Agneta Yngve Editor-in-Chief

Mark L Wahlqvist

Division of Preventive Medicine and Health Services

Research

Institute of Population Health Sciences National Health Research Institutes 35 Keyan Road Zhunan, Miaoli County 350

Taiwan, ROC

\section{References}

1. US Energy Information Administration (2009) The Residential Energy Consumption Survey (RECS). Cooking Trends from 1993 to 2001. Cooking Trends in the United States: Are We Really Becoming a Fast Food Country? http://www.eia.gov/emeu/recs/cookingtrends/cooking.html (accessed April 2012).

2. Wahlqvist ML (2009) Connected Community and Household Food-Based Strategy (CCH-FBS): its importance for health, food safety, sustainability and security in diverse localities. Ecol Food Nutr 48, 457-481.

3. Chen RC-Y, Lee MS, Chang YH et al. (2012) Cooking frequency may enhance survival in Taiwanese elderly. Public Health Nutr 15, 1142-1149.

4. Chang Y-H, Chen RC-Y, Wahlqvist ML et al. (2011) Frequent shopping by men and women increases survival in the older Taiwanese population. J Epidemiol Community Health; doi:10.1136/jech.2010.126698, First published online: 6 April 2011.

5. Bernhardt C (2012) One foot in the gravy: the rise of cookery classes for older men. The Guardian, 10 April; available at http://www.guardian.co.uk/society/2012/apr/ 10/cookery-classes-older-men

6. Diez Roux AV (2003) Residential environments and cardiovascular risk. J Urban Health 80, 569-589. 